NBER WORKING PAPER SERIES

\title{
CAN INNOVATORS BE CREATED? EXPERIMENTAL EVIDENCE FROM AN INNOVATION CONTEST
}

Joshua S. Graff Zivin

Elizabeth Lyons

Working Paper 24339

http://www.nber.org/papers/w24339

\author{
NATIONAL BUREAU OF ECONOMIC RESEARCH \\ 1050 Massachusetts Avenue \\ Cambridge, MA 02138 \\ February 2018
}

We thank participants at the May, 2016 Innovation Growth Lab Research Meeting and those at the 5th AIEA-NBER conference. We gratefully acknowledge funding support from the Kauffman Foundation and the National Science Foundation through its SciSIP Program (Award SBE-1460344). This study is included in the AEA RCT Registry (AEARCTR-0001857). The views expressed herein are those of the authors and do not necessarily reflect the views of the National Bureau of Economic Research.

NBER working papers are circulated for discussion and comment purposes. They have not been peer-reviewed or been subject to the review by the NBER Board of Directors that accompanies official NBER publications.

(C) 2018 by Joshua S. Graff Zivin and Elizabeth Lyons. All rights reserved. Short sections of text, not to exceed two paragraphs, may be quoted without explicit permission provided that full credit, including ( notice, is given to the source. 
Can Innovators be Created? Experimental Evidence from an Innovation Contest

Joshua S. Graff Zivin and Elizabeth Lyons

NBER Working Paper No. 24339

February 2018

JEL No. J24,M54,O32

\begin{abstract}
$\underline{\text { ABSTRACT }}$
Existing theories and empirical research on how innovation occurs largely assume that innovativeness is an inherent characteristic of the individual and that people with this innate ability select into jobs that require it. In this paper, we investigate whether people who do not self-select into being innovators can be induced to innovate, and whether they innovate differently than those who do self-select into innovating. To test these questions, we designed and implemented an innovation contest for engineering and computer science students which allowed us to differentiate between those who self-select into innovative activities and those who are willing to undertake them only after receiving an additional incentive for doing so. We also randomly offer encouragement to subsets of both the induced and self-selected contest participants in order to examine the importance of confidence-building interventions on each sample. We find that while induced participants have different observable characteristics than those that were 'innately' drawn to the competition, on average, the success of induced participants was statistically indistinguishable from their self-selected counterparts and encouragement does not change this result. Heterogeneity in treatment effects suggests an important role for the use of targeted interventions.
\end{abstract}

Joshua S. Graff Zivin

University of California, San Diego

9500 Gilman Drive, MC 0519

La Jolla, CA 92093-0519

and NBER

jgraffzivin@ucsd.edu

Elizabeth Lyons

School of Global Policy and Strategy

University of California, San Diego

9500 Gilman Drive, MC 0519

La Jolla, CA 92093-0519

lizlyons@ucsd.edu 


\section{Introduction}

Innovation has long been viewed as important for productivity and income growth (Grossman and Helpman, 1994; Solow, 1957). Therefore, understanding the conditions under which productivity enhancing innovation occurs is critical for understanding economic development more generally. Recent research has examined incentive design for encouraging appropriate levels of experimentation (Azoulay et al., 2011; Ederer and Manso, 2011; Holmstrom, 1989), how governments may be able to increase innovative activity through trade and immigration policy (Grossman and Helpman, 1990; Oettl and Agrawal, 2008), and how intellectual property policy can provide incentives to innovate and learn from others (Scotchmer, 1991). While these studies provide important evidence on tools to increase innovative output, they all implicitly assume that the population of innovators is fixed and, thus, that efforts to increase innovation should be directed at these existing innovators. ${ }^{1}$

In this paper, we use a randomized control trial (RCT) to explore the validity of this assumption. More specifically, we examine whether successfully innovating requires an innate predisposition by testing whether people who do not self-select into being innovators can be induced to innovate, and whether they innovate differently than those who do self-select into innovating. In particular, our study allows us to address three inter-related questions:

1. Is the desire to innovate innate or is it sufficiently pliable that it can be induced?

2. Are induced innovators less able to innovate than those who naturally gravitate to innovative activities?

3. What is the impact of encouragement on the performance of innovators, and does this differ between innate and induced innovators?

Understanding whether innovators can be created, and how they fare relative to those who self-select into innovative activities, has important implications for public and private policy. Should innovation policy and strategy limit its attention to optimizing conditions for the workforce already engaged in that space or might they be better served by designing institutions and incentives to lure more individuals into the fray? If incumbents and induced entrants differ in the quantity and quality of their innovative output, what is the

\footnotetext{
${ }^{1}$ Research on entrepreneurs as innovators has begun to examine key characteristics of entrepreneurs and what leads them to enter into self-employment. Both pre-founding work experience (e.g. Elfenbein et al., 2010), training (e.g. Lyons and Zhang, 2017), and genetics (Nicolaou et al., 2008) appear to impact the decision to become an entrepreneur. While the latter is consistent with the notion that innovative ability is innate, the impacts of work experience are potentially consistent with our contention that innovators can also be created. Given that would-be entrepreneurs chose their early work experience, more evidence is needed to substantiate this claim. Moreover, entrepreneurs are only a subset of innovators and their characteristics may not generalize to non-entrepreneur innovators. For example, in addition to innovation, entrepreneurs' responsibilities include labor management, securing financing, and marketing. Someone with a preference and the ability to innovate may not have the desire to take on these additional responsibilities as well as the risks that innovation within an existing organization does not involve.
} 
optimal mix of efforts to expand the knowledge frontier? Moreover, understanding whether innovative talent is innate provides novel insights about the distribution of rents that arise from new inventions. If innovative talent is entirely a quiddity, organizations will have to provide large amounts of compensation to attract scarce innovators to the firm (e.g. Acemoglu, 1998). If, however, innovators can be created, compensation to innovators will be disciplined by potential new entrants and the cost of creating them (e.g. Acemoglu and Pischke, 1998). Moreover, if induced innovators are portable, firms may under-invest in creating them (Becker, 1962).

More generally, examining the potential for growing the pool of innovators has important implications for our understanding of the innovation process and possible avenues for increasing inventive output. In particular, our study allows us to determine whether individuals who do not choose to innovate in the absence of an intervention are being held back by accurate beliefs about their ability to perform, or by psychological barriers that, if overcome, could meaningfully contribute to the innovation process. ${ }^{2}$

The RCT we implemented to interrogate these research questions was undertaken within an innovation contest for undergraduate engineering and computer science students at UC San Diego (UCSD). Our design, described in detail in Section 3, allows us to compare self-selected innovators to a population of potential innovators with identical training, and to test whether the non-self-selected individuals can successfully innovate. Moreover, it allows us to assess the differential effects of confidence boosting messages across these populations to determine whether this type of managerial intervention impacts innovative outcomes, and whether the induced innovators' performance benefits more from these efforts. In addition, by observing actual innovative output through the innovation contest, we are able to determine whether innate and induced innovators have different innovative skills.

As expected, those participants that were induced to participate were different than those that volunteered based on observable characteristics. By design, the induced sample was more female, but induced participants were also less likely to be drawn from majors that provide the most relevant skills for the competition and had lower cumulative GPAs. Yet, despite appearing to be less well equipped to compete, the success of induced participants was statistically indistinguishable from those that were 'innately' drawn to the competition. Thus, at least on average, it looks like innovators can be created.

The impacts of encouragement on competition outcomes were a bit more surprising. Encouragement

\footnotetext{
${ }^{2}$ We designed our sampling frame to allow us to test whether females are more likely to be impacted by interventions to encourage entry into innovation. Given that females are under-represented in STEM jobs (Beede et al., 2011), they may be a particular important target for firm and public policies that are aimed at expanding the pool of innovators. However, we did not find robust differential treatment effects for females and males (see Appendix Tables A1 and A2), and, therefore, do not focus on this dimension of our study in this paper.
} 
appears to have no effect on any of our outcomes of interest. ${ }^{3}$ Moreover, it does not appear to have a differential effect for those induced, suggesting that confidence boosting is not essential for the reluctant participants once they are induced to participate.

While induced participants do as well as those that initially volunteer and neither group appears to benefit from encouragement on average, as predicted by the framework that motivates our experimental design (see Section 2), these average effects mask important heterogeneity in the impacts of each treatment arm. In particular, the impacts of inducement are significantly less promising for lower ability students, as proxied by cumulative GPA. At the same time, they are helped by encouragement. The impacts on high ability students are much more surprising. Not only do they not benefit from this encouragement, but they appear to be harmed by it.

Combined, our results demonstrate that innovators can be created through inducement subsidies, but that targeting inducement is likely to be more cost effective especially since targeting can be based on information like GPA that is relatively easy to collect. Moreover, we demonstrate that encouragement may also need to be targeted to focus on those who benefit from it while avoiding those it may harm.

The paper proceeds as follows; Section 2 motivates our experiment design, Section 3 describes our research setting and experiment, and Section 4 describes our data and analysis, Section 5 presents our findings, and Section 6 summarizes and concludes.

\section{Motivating Framework}

We begin with a simple and stylized framework to motivate our experimental treatment groups and experimental analysis. In particular, the framework allows for different preferences and abilities for innovative activities. The utility function used in the framework is consistent with our setting, but intended to be general enough to be useful in other settings as well.

\section{$2.1 \quad$ Framework set-up}

There are $n$ workers who each have an innovative type $\alpha$. This $\alpha$ may affect a worker's cost of innovative activities, their expected likelihood of a successful innovative activity outcome, or both. For simplicity, assume

\footnotetext{
${ }^{3}$ While encouragement does not affect outcomes, survey evidence suggests that it does increase the perception that contestants do not have enough time to complete their project amongst those that do not ultimately submit a final proposal. Since our encouragement design included reminders about the competition deadline it may have made time scarcity more salient for those that were falling behind on their project.
} 
there are two possible $\alpha$ 's. ${ }^{4}$ Workers are presented with an opportunity to spend time on an innovative activity, referred to as an "innovation contest" that will pay them $R$ if they succeed. Each worker succeeds with some probability $p\left(\right.$ success $\left.\mid \alpha_{i}\right)$. Each worker $i$ has a cost $c\left(\alpha_{i}\right)$ of spending time on the contest. Therefore, worker $i$ 's expected utility from participating in the innovation contest is $E\left(U_{i} \mid \alpha_{i}\right)=p\left(\right.$ success $\left.\mid \alpha_{i}\right) R-c\left(\alpha_{i}\right)$. Alternatively, workers can spend time on some outside option $O$. For simplicity, we assume the value of this outside option is the same across workers.

Suppose that $E\left(U_{i} \mid \alpha_{1}\right) \geq E\left(U_{i} \mid \alpha_{2}\right)$ either because $p\left(\right.$ success $\left.\mid \alpha_{1}\right) \geq p\left(\right.$ success $\left.\mid \alpha_{2}\right)$, or $c\left(\alpha_{1}\right) \geq c\left(\alpha_{2}\right)$, or both. In addition, suppose that $E\left(U_{i} \mid \alpha_{1}\right) \geq O \geq E\left(U_{i} \mid \alpha_{2}\right)$ so that only workers with $\alpha_{1}$ participate in the innovation contest. Going forward, we refer to these workers as "innate innovators". This is consistent with the idea that, all else equal, some people are more likely to select into innovative activities than others.

\subsection{Subsidy Introduction}

Suppose now that those who have not selected into the innovation contest are offered some subsidy $S$ to participate in it. As a result, their expected utility from participating is now: $E\left(U_{i} \mid \alpha_{2}\right)=p\left(s u c c e s s \mid \alpha_{2}\right) R-$ $c\left(\alpha_{2}\right)+S$. Importantly, $S$ does not affect $p\left(\right.$ success $\left.\mid \alpha_{i}\right)$. To avoid generating an income effect from the subsidy in which $S$ is differentially affecting $p\left(\right.$ success $\left.\mid \alpha_{2}\right)$, the subsidy is subsequently offered to $\alpha_{1}$ type workers as well, albeit after they have elected to participate in the study to avoid influencing their participation decision. ${ }^{5}$ Suppose further than $S$ is high enough that $E\left(U_{i} \mid \alpha_{2}\right) \geq O$ so that the non-innate workers now also join the contest. Going forward, we refer to these workers as "induced innovators".

If $E\left(U_{i} \mid \alpha_{1}\right) \geq E\left(U_{i} \mid \alpha_{2}\right)$ because $p\left(\right.$ success $\left.\mid \alpha_{1}\right) \geq p\left(\right.$ success $\left.\mid \alpha_{2}\right)$, and $c\left(\alpha_{1}\right)$ is not less than $c\left(\alpha_{2}\right)$, then innate innovators are more likely to succeed in the innovation contest than induced innovators are. This implies that innate innovators select into innovation because they have high innovative abilities.

Alternatively, if $E\left(U_{i} \mid \alpha_{1}\right) \geq E\left(U_{i} \mid \alpha_{2}\right)$ because $c\left(\alpha_{2}\right) \geq c\left(\alpha_{1}\right)$, and $p\left(\right.$ success $\left.\mid \alpha_{1}\right)$ is not greater than $p\left(\right.$ success $\left.\mid \alpha_{2}\right)$, then innate innovators are no more likely to succeed in the innovation contest than induced innovators are. ${ }^{6}$ This implies that innate innovators select into innovation because they have lower costs of doing so, for instance, because they enjoy it more. ${ }^{78}$

\footnotetext{
${ }^{4}$ In reality, there are a continuum of $\alpha$ types. This framework focuses on those at the margin of selecting into innovation. Our experiment is not targeted at inducing workers who require a very large subsidy to participate in innovative activities and we therefore do not consider how our treatments are likely to affect them.

${ }^{5}$ Note that if $\alpha_{1}$ type workers are better able to use $S$ in their innovative activity because they have better abilities, than $S$ may differentially affect worker types' likelihood of success. Given the small size of $S$ in the actual experiment, we do not think it is likely to have a meaningful affect on success likelihoods.

${ }^{6}$ In this case, induced innovators may also have higher costs of innovation.

${ }^{7}$ If we let the value of outside options vary across worker types, this result could come up because workers with $\alpha_{2}$ have higher value outside options.

${ }^{8}$ Although we are only allowing for one possible low $\alpha$ type in our model, in reality, it is possible that there are both low $\alpha$
} 
Therefore,

Proposition 1 If innate and induced innovators differ in their probability of successfully innovating, then, conditional on the cost of innovating being incurred, induced innovators should perform worse than innate innovators.

Proposition 2 If innate and induced innovators differ in their cost of innovation, then, conditional on the cost of innovating being incurred, they should perform no differently on innovative activities.

\subsection{Encouragement Intervention}

Suppose now that managers can intervene in workers' innovative activities in an effort to increase $p\left(s u c c e s s \mid \alpha_{i}\right)$. Specifically, they can undertake a confidence boosting intervention where confidence is defined as a worker's belief in their likelihood of success in innovation. Imagine this intervention increases $p\left(s u c c e s s \mid \alpha_{i}\right)$ if a worker's $i$ is below some threshold. This may be the case if, for instance, lack of confidence causes poor performance due to anxiety-induced choking (Compte and Postlewaite, 2004) but that the intervention cannot raise confidence above a certain level due to practical constraints. ${ }^{9}$ Managers cannot observe ex-ante which worker's are under-confident. If what differentiates $\alpha_{1}$ and $\alpha_{2}$ types is how confident in their abilities they are, then this managerial intervention will raise $p\left(\alpha_{2}\right)$ by more than $p\left(\alpha_{1}\right)$. Therefore,

Proposition 3 If high and low type innovators differ in self-confidence, then managerial interventions aimed at increasing worker confidence in their abilities will increase innovative activity performance among low type innovators $\left(\alpha_{2} s\right)$ more than it will among high type ones $\left(\alpha_{1} s\right)$.

\section{Experimental Design}

\subsection{Research Setting \& Population}

To address our research questions, we implemented an RCT within an innovation contest for a subset of students who are arguably most at risk of entering innovative careers. In particular, we introduced an innovation contest open to all undergraduate engineering and computer science students at UCSD for which participants were required to design and/or develop an application that helps people fall asleep faster based

types that have higher costs of innovating but similar abilities to those of innate innovators, and low $\alpha$ types that have lower likelihoods of success than innate innovators. We test for this possibility empirically in section 5 .

${ }^{9}$ We do not believe that our confidence-boosting intervention has the potential to lead to over-confidence in workers which could negatively impact performance (Barber and Odean, 2001). Our intervention will provide encouragement rather than suggest to workers that they have exception skills. 
on their personal preferences. This problem was defined through discussions with several executives and entrepreneurs in technology industries, some of whom served as contest judges. It is both an important problem that does not yet have an ideal solution, and one that we believed the undergraduate students could make reasonable progress on within a three month window. Prior to the contest sign-up deadline, students were told that the innovation contest would require them to submit an application that solves a specified problem related to personalization, but were not told about the specific problem until after the sign-up deadline. ${ }^{10}$

Students were invited to enroll in the contest through a series of newsletters and emails that were supplemented with two information sessions between December, 2016 and January, 2017. The contest began on February 8, 2017 and had a deadline of May 27, 2017. Contest winners were announced approximately two weeks later during an awards ceremony and pitch event. The Engineering Department in which our target participants are enrolled has been ranked in the top 10 globally (US News \& World Report, 2016) and offers "...a broad and rigorous curriculum designed to provide students with the strong academic education and technical training necessary for placement in the competitive high-tech job market as well as for advanced studies in graduate school." We selected this population because these students will have the technical capabilities to produce impactful inventions in their lifetime, and because engineers are frequently the targets of interventions to increase innovative activity (e.g. Bureau of Labor Statistics, 2013). In total, 190 students signed up for the contest.

Submissions made by the contest deadline were evaluated by five technology industry participants who helped us identify the contest problem and acted as judges for the contest output. They evaluated each submission across four categories; functionality, user-friendliness, novelty, and potential commercial value and provided a score of 1-5 on each category for a total score maximum of 20 . The developers of the top three applications were awarded prize money. First place received $\$ 5,000$, second place received $\$ 2,000$, and third place received $\$ 1,000$. Participants were instructed to submit any output they had at the time of the deadline, including written plans, design mock-ups, minimum viable products, and beta apps. To maximize design flexibility, submissions could be intended for any platform.

\subsection{Treatments}

In order to differentiate between innate and induced innovators, a random subset of eligible students who did not sign up by the contest deadline were offered a monetary incentive to participate in the contest,

\footnotetext{
${ }^{10}$ This was to ensure that students who signed up early would not have a mechanical advantage over those who signed up later.
} 
specifically a $\$ 100$ visa gift card. Taking up this offer did not require students to do anything more than put their name on the list of contest participants, and agree to receive emails about the contest. This incentive is our inducement treatment, which is designed to 'create' innovators from a sample that did not self-identify as such. In order to provide this incentive, the contest sign-up deadline was extended by one week. Students who had already signed up to participate were informed about the sign-up deadline extension and monetary incentive being offered to some students to increase the participant pool. Moreover, they were also told they would receive the same amount of money being offered to the students who had not yet signed up. ${ }^{11}$ The emails sent to both the students in our inducement treatment, and to the students who had self-selected into the contest without inducement are provided in Appendix B. The innovation contest began the day after the extended contest sign-up deadline, when the contest problem was revealed to students. ${ }^{12}$

To determine the differential effect of a managerial intervention aimed at raising confidence on the selfselected and induced populations, a random subset of each group received a schedule of confidence boosting emails throughout the contest period. In total, four emails were sent every two weeks with the exception of the first three weeks during which all participants were receiving regular emails about the details of the contest, and the final two weeks of the contest when all participants received a series of reminder emails. The text included in the emails differs from one email to the next, but they are all written to provide versions of messages that have been shown to correlate with employee satisfaction and productivity in organizational behavior research (e.g. Amabile and Pratt, 2016). For example, the emails sent to participants in the encouragement treatment were designed to convey to participants that they are making a meaningful contribution to their future careers and to the development of sleep technologies through their participation. We also provided them links to resources for students working on their innovative capabilities at UCSD. The complete texts of each email are included in Appendix B.

With this set up, we have four treatment groups (see Figure I). In total, 103 eligible students signed up to participate before the initial sign-up deadline ${ }^{13}$, and 87 eligible students who received the inducement treatment signed up before the extended sign-up deadline. This is out of a total of 3,445 Engineering and Computer Science Department undergraduate students of which 1,000 received the inducement treatment email. ${ }^{14}$ Our sample sizes per treatment arm are as follows: 52 participants in the self-selected, no man-

\footnotetext{
${ }^{11}$ Offering the money to all participants reduces concerns about income effects increasing the ability of participants to successfully innovate. Those who sign up before the initial deadline were not expecting this payment so it will not bias our measure of intent.

${ }^{12}$ Given our intention to test heterogeneous treatment effects across females and males, we oversampled females in our inducement treatment email because only $24 \%$ of eligible students are female. As a result of this oversampling, $50 \%$ of the students who received the inducement treatment were female.

${ }^{13}$ This represents about $2 \%$ of the eligible population.

${ }^{14} \mathrm{~A}$ take up of about $9 \%$ suggests that students who did sign up after the inducement treatment email did not do so just to
} 
agerial intervention group; 51 in the self-selected with managerial intervention group; 44 in the induced, no managerial intervention group; and 43 in the induced with managerial intervention group.

Figure I: Treatment Groups

\begin{tabular}{lcc}
\hline & No Managerial Intervention & Managerial Intervention \\
\hline Self-Selected Innovators & $\mathrm{n}=52$ & $\mathrm{n}=51$ \\
Induced Innovators & $\mathrm{n}=44$ & $\mathrm{n}=43$ \\
\hline
\end{tabular}

\section{Data \& Analysis}

All participants were asked to complete a basic survey when they signed up for the contest. The survey asked participants for their degree majors, gender, year of study, GPA, and whether they have previously participated in an innovation contest.

We collected outcome data based on whether or not participants submitted a project for consideration by the judges, and the judges' scoring of projects that were submitted. Each project was scored by three judges. Our preferred measure of the quality of submissions is the average ranking judges gave each project. Each judge scored 7 projects, so this measure ranges from 1-7 with 7 as the highest and 1 as the lowest. We prefer this measure for two reasons. First, we are analyzing a competition in which the highest ranked project wins. Second, our ranking measure captures the idiosyncratic scoring rubric for each judge without the need for normalizations that can be hard to interpret. Including judge fixed effects in our context is impractical because projects were judged by three people and no three judges evaluated the same 7 projects which leaves very few observations within each judge-triad. Our findings are robust to alternative measures, including normalized average scores, as shown in Appendix Table A3.

We also ran a survey following the conclusion of the contest to ask participants about their experience in the contest, including whether they spent any time on the contest problem and, if they did not submit something for consideration, why they chose not to. There were four versions of the survey, one for each treatment group combination, where each shared a common group of questions as well as some that were specific to their treatment status. As detailed below, these survey results will be used to probe possible mechanisms for our findings.

receive the $\$ 100$ gift card. 


\subsection{Summary Statistics and Measurement}

Mean participant characteristics based on pre-contest participant survey responses are provided in Panel A of Table I. These statistics demonstrate that about one-third of participants are female, the majority are enrolled in a computer science (CS) or electrical engineering (EE) major, participants are in their third year of study on average, and a small minority have prior innovation contest experience. In addition, the average cumulative GPAs of participants are quite high. CGPA is measured using response data from a survey question in which we asked participants to indicate which category their cumulative GPA falls into on a scale from 1-6 with 1 being less than 2.0, 2 being 2.0-2.49, 3 being 2.50-2.99, 4 being 3.0-3.49, 5 being 3.50-3.99, and 6 being 4.0. The sample mean suggests an average participant CGPA of about 3.5.

Contest performance summary statistics are presented in Panel B of Table I. About one-tenth of participants submitted a project for consideration by the judges. Conversations with organizations and individuals who regularly run innovation contests and hackathons provide anecdotal evidence that this is a typical submission rate. In order to treat both the act of submitting and the quality of that submission as an endpoint of interest, we generate an outcome variable using a combination of whether or not someone submitted, and the project rank conditional on submitting. In particular, Average Ranking is equal to zero if a participant did not submit a project and equal to their average ranking if they did. Consistent with the fact that many participants did not submit a project for consideration by the judges, the mean of our outcome variable is 0.33. We verify that our findings are consistent with alternative measures that account for the large number of zeros in this measure. ${ }^{15}$

Panel C of Table I presents summary statistics for three survey-based measures of contest engagement. The first thing to note is that 78 of the contest participants completed the survey, representing about $41 \%$ of the population of students who signed up to participate in the contest. As we discuss in section 5, those who filled in the survey appear similar to those who did not on observable characteristics, but, not surprisingly, were on average more engaged in the contest than those who did not complete the post-contest survey. Among this selected population, close to $70 \%$ did spend some time on the contest problem but only $22 \%$ of these participants ended up submitting a project for consideration by the judges. Among those who did not spend any time on the contest or spent time but did not submit a project for consideration, about half indicated that time constraints were their primary reason for not submitting a project, and another $40 \%$ indicated that the difficulty associated with the contest problem was their primary reason for not submitting

\footnotetext{
${ }^{15}$ In particular, we use the inverse hyperbolic sine transformation (Ramirez et al., 1994) to generate an alternative outcome variable of interest. Analyses using this and other alternative outcome measures are presented in Appendix Table A3.
} 
a project. ${ }^{16}$ We use this data to explore possible mechanisms for our main findings in section 5.5.

Table I: Summary Statistics

\begin{tabular}{lccc}
\hline \hline & Mean & Std. Dev. & N \\
\hline Panel A: Participant Characteristics & & & \\
Female & 0.332 & $(0.472)$ & 190 \\
Weighted Female & 0.261 & $(0.386)$ & 190 \\
CS or ElecEng Major & 0.702 & $(0.459)$ & 190 \\
Weighted CS or ElecEng Major & 0.649 & $(0.429)$ & 190 \\
Year of Study & 3.005 & $(1.261)$ & 183 \\
CGPA (1-6) & 4.392 & $(0.901)$ & 176 \\
Prior Contest Experience & 0.131 & $(0.338)$ & 190 \\
& & & \\
Panel B: Outcomes & & & \\
Average Ranking (0 if not submission) & 0.332 & $(1.164)$ & 190 \\
Submitted Project & 0.090 & $(0.285)$ & 190 \\
Average Ranking Score Conditional on Submitting & 3.715 & $(1.630)$ & 17 \\
& & & \\
Panel C: Survey Responses & & & \\
Any Effort Invested in Contest & 0.679 & $(0.47)$ & 78 \\
Did not Submit due to Time Constraints & 0.470 & $(0.503)$ & 66 \\
Did not Submit due to Challenge & 0.409 & $(0.495)$ & 66 \\
\hline
\end{tabular}

Notes:Female and CS/Elec Eng Major weighted to account for over sampling in induced treatment.

\subsection{Treatment Effects Estimation}

Since our study provides random assignment of treatments, our analysis will focus both on mean comparisons across treatment groups and regression analyses. We begin by presenting the effects of the inducement treatment on selection into the contest, and then turn our attention to performance among those who participate in the contest. Importantly, because we expect that the primary mechanism through which inducement will affect outcomes is through selection into participation, our preferred empirical specification does not include controls for participant characteristics. Nonetheless, we also present results that include controls for participant characteristic covariates to illustrate the role they are playing in our core findings.

We follow this by separately analyzing the impacts of the encouragement treatment on participant performance. The encouragement treatment was randomly assigned to participants who had already selected into the contest, so we do not expect that participant characteristics will vary by encouragement treatment (comparisons are presented in section 5). As with inducement, we nonetheless run our regression analysis of

\footnotetext{
${ }^{16} \mathrm{~A}$ small percentage of participants indicated their primary reason for not submitting a project for consideration was because the contest problem was not sufficiently interesting for them to spend time on.
} 
the effects of encouragement on outcomes with and without controls for these characteristics.

Since encouragement may differentially influence the induced and innate samples, we also analyze the following equation:

$$
Y_{i}=\alpha+\beta_{1} \text { Inducement }_{i}+\beta_{2} \text { Encouragement }_{i}+\beta_{3}\left(\text { Inducement }_{i} * \text { Encouragement }_{i}\right)+\epsilon_{i}
$$

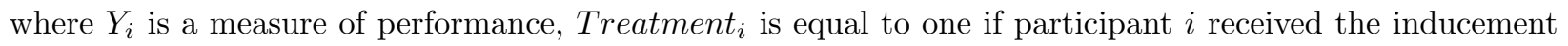
treatment, and Encouragement ${ }_{i}$ is equal to one if participant $i$ received the encouragement treatment. ${ }^{17}$

As our framework presented in section 2 demonstrates, we expect our treatments will have different impacts depending on student ability. Using cumulative GPA as our most comprehensive measure of ability, we assess this directly by estimating the following equation:

$$
\left.Y_{i}=\alpha_{i}+\beta_{1}\left(\text { Treatment }_{i}\right)+\beta_{2}\left(\text { HighCGPA }_{i}\right)+\beta_{3} \text { (Treatment }_{i} * \text { HighCGPA }_{i}\right)+\epsilon_{i}
$$

where $Y_{i}$ is a measure of performance or participation, Treatment $t_{i}$ is equal to one if participant $i$ received

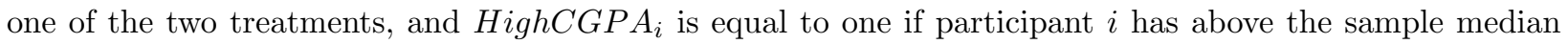
cumulative GPA. We estimate these equations separately for the encouragement and inducement treatments.

\section{Results}

The presentation of our results follow the progression described in the previous section. We begin with estimates of the overall impacts of the inducement and encouragement treatments as well as the interaction between the two. This is followed by an analysis of heterogeneity in our treatment effects by ability and an exploration of the potential mechanisms that might underlie these findings.

\subsection{Average Effects of Receiving an Inducement to Innovate}

\subsubsection{Selection into Participation}

Table II presents comparisons of mean participant characteristics by inducement treatment. As expected, these comparisons demonstrate important differences between the population of participants who signed up without receiving a subsidy for participating and those who only did so with a subsidy. By design,

\footnotetext{
${ }^{17}$ We also verify that all of our estimates of treatment effects on whether or not participants submit a project for consideration are robust to using probit regressions.
} 
the induced sample was more female. More importantly, induced participants were also less likely to be drawn from majors that provide the most relevant skills for the competition, even when we account for the over sampling of these majors in our inducement treatment assignment, and had lower cumulative GPAs. Consistent with the predictions of our conceptual framework, inducement appears to lead lower ability students to participate by increasing the pay-offs to participation. ${ }^{18}$

Table II: Mean Participant Characteristic Comparisons by Inducement Treatment

\begin{tabular}{lccc}
\hline \hline & Not Induced & Induced & p-value \\
\hline \multirow{2}{*}{ Female } & 0.252 & 0.425 & $0.009^{* * *}$ \\
& $(0.043)$ & $(0.054)$ & \\
Weighted Female & 0.252 & 0.272 & 0.726 \\
CS or ElecEng Major & $(0.043)$ & $(0.034)$ & \\
& 0.789 & 0.605 & $0.006^{* * *}$ \\
Weighted CS or ElecEng & $(0.040)$ & $(0.053)$ & \\
& 0.786 & 0.487 & $0.000^{* * *}$ \\
Year of Study & 0.040 & 0.042 & \\
& 2.941 & 3.111 & 0.365 \\
CGPA (1-6) & $(0.120)$ & $(0.146)$ & \\
& 4.500 & 4.274 & $0.096^{*}$ \\
Above Median CGPA & $(0.091)$ & $(0.101)$ & \\
& -.663 & 0.521 & $0.065^{*}$ \\
Prior Contest Experience & $(0.049)$ & $(0.060)$ & \\
& 0.163 & 0.093 & 0.154 \\
$\mathrm{~N}$ & $(0.036)$ & $(0.032)$ & \\
& 104 & 86 & \\
\hline
\end{tabular}

Notes: Standard deviations are in parentheses. Female and CS/Elec Eng Major weighted to account for over sampling in induced treatment. ${ }^{*}$ significant at $10 \%$; ** significant at $5 \%$; *** significant at $1 \%$

\subsubsection{Impact on Outcomes}

Despite the mean comparisons presented in Table II suggesting that the induced participants may be less well equipped to compete, the success of these participants appears statistically indistinguishable from those that were 'innately' drawn to the competition. In particular, mean outcomes across induced and innate innovators presented in Table III demonstrate that induced participants have slightly lower mean submission rates and scores than innate innovators, but that these differences are statistically insignificant and quite small.

\footnotetext{
${ }^{18}$ One possible concern with the inducement treatment is that those who signed up after the receiving it did so because they did not see any of the contest announcements that were sent out prior to the inducement treatment. We think this is unlikely for several reasons. First, the Engineering and Computer Science department, and the entrepreneurship center located within the department sent out numerous emails to students about the contest over a two month period. Therefore, even if the induced population did not read the emails announcing the contest, they would have chosen not to based on the subject line that made clear there was a contest being announced which suggests they self-selected out of the contest based on their preferences. Second, we asked participants in the inducement treatment why they had not signed up prior to receiving the subsidy offer in the post-contest survey, and while some stated they were not aware of the contest, many others stated that they thought they didn't have the time or ability to participate in it.
} 
Table III: Mean Outcomes by Inducement Treatment

\begin{tabular}{|c|c|c|c|}
\hline & Not Induced & Induced & p-value \\
\hline Average Ranking & $\begin{array}{c}0.390 \\
(0.126)\end{array}$ & $\begin{array}{c}0.264 \\
(0.108)\end{array}$ & 0.460 \\
\hline Submitted Project & $\begin{array}{c}0.096 \\
(0.029)\end{array}$ & $\begin{array}{c}0.081 \\
(0.030)\end{array}$ & 0.725 \\
\hline Average Ranking Conditional on Submitting & $\begin{array}{c}4.016 \\
(0.497)\end{array}$ & $\begin{array}{c}3.285 \\
(0.653)\end{array}$ & 0.379 \\
\hline $\mathrm{N}$ & 104 & 86 & \\
\hline
\end{tabular}

Notes: Standard deviations are in parentheses. Female and CS/Elec Eng Major weighted to account for over sampling in induced treatment. * significant at $10 \% ; * *$ significant at $5 \% ; * * *$ significant at $1 \%$

We verify that the average effect of the inducement treatment on outcomes is zero using regression analysis and present these results in Table IV. Columns 1 and 2 present the estimated effect of inducement on whether or not a participant submits a project for consideration, columns 3 and 4 present the estimated effect of inducement on average project rankings, and columns 5 and 6 present the inducement treatment effect estimates on average project rankings conditional on making a submission to the contest. Columns 1 , 3 , and 5 do not include controls for participant characteristics, with those added in columns 2,4 , and 6 . In all specifications, the effect of inducement on outcomes is insignificant.

Table IV: Effect of Inducement Treatment on Outcomes

\begin{tabular}{lcccccc}
\hline \hline & $\begin{array}{c}(1) \\
\text { Submission }\end{array}$ & $\begin{array}{c}(3) \\
\text { Average Ranking }\end{array}$ & $\begin{array}{c}(4) \\
\text { Average Ranking } \\
\text { Conditional on Submitting }\end{array}$ \\
\hline Inducement Treatment & -0.017 & -0.024 & -0.126 & -0.190 & -0.732 & -0.527 \\
& $(0.0418)$ & $(0.0475)$ & $(0.170)$ & $(0.191)$ & $(0.806)$ & $(0.846)$ \\
Controls & No & Yes & No & Yes & No & Yes \\
Observations & 190 & 172 & 190 & 172 & 17 & 17 \\
R-squared & 0.001 & 0.025 & 0.003 & 0.046 & 0.052 & 0.404 \\
Mean dep var & 0.090 & 0.090 & 0.510 & 0.510 & 2.824 & 2.824 \\
\hline
\end{tabular}

Notes: Standard errors are in parentheses. Columns 2, 4, and 6 include controls for participant gender, cgpa, year of study, whether or not they major in computer science or electrical engineering, and whether or not they have prior innovation contest experience. * significant at $10 \% ; * *$ significant at $5 \% ; * * *$ significant at $1 \%$

Thus, at least on average, it looks like effective innovators can be 'created' through a simple inducement. It is, however, noteworthy that the addition of controls for participant characteristics has a sizable effect on the point estimates for the average proposal scores conditional on submitting, suggesting a potentially important role for heterogeneity that we will return to below. 


\subsection{Average Effects of Receiving an Encouragement During the Contest}

We are now ready to turn to the estimated effects of the encouragement treatment on participant outcomes. Table V presents mean comparisons between participants who did and did not receive the encouragement treatment. As described earlier, the encouragement treatment was randomly assigned to all participants so participants who received the encouragement treatment should look the same as those who did not. Panel A on Table V largely confirms this with one minor exception. There is a small statistically significant difference at the $10 \%$ level in whether or not a participant is in a computer science or electrical engineering major. To ensure this difference is not impacting our findings, we confirm that all our results are robust to controlling for it.

Panel B of Table V presents mean outcomes by encouragement treatment status. As in the case of the inducement treatment, encouragement does not appear to have any significant impact on participant outcomes in the contest.

Table V: Mean Comparisons by Encouragement Treatment

\begin{tabular}{lccc}
\hline \hline & Not Encouraged & Encouraged & p-value \\
\hline Panel A: Participant Characteristics & & & \\
Female & 0.375 & 0.287 & 0.201 \\
& $(0.050)$ & $(0.047)$ & \\
CS or ElecEng Major & 0.760 & 0.648 & $0.093^{*}$ \\
& $(0.044)$ & $(0.049)$ & \\
Year of Study & 2.901 & 3.130 & 0.218 \\
& $(0.137)$ & $(0.125)$ & \\
CGPA (1-6) & 4.427 & 4.356 & 0.604 \\
& $(0.100)$ & $(0.092)$ & \\
Above Median GPA & 0.577 & 0.570 & 0.918 \\
& $(0.050)$ & $(0.052)$ & \\
Prior Contest Experience & 0.135 & 0.128 & 0.875 \\
& $(0.035)$ & $(0.035)$ & \\
Panel B: Outcomes & & & \\
Average Ranking & 0.369 & 0.294 & 0.656 \\
& $(0.118)$ & $(0.121)$ & \\
Submitted Project & 0.104 & 0.074 & 0.476 \\
Average Ranking Conditional on Submitting & $(0.031)$ & $(0.027)$ & \\
& 3.583 & 3.904 & 0.702 \\
$\quad \mathrm{~N}$ & $(0.415)$ & $(0.792)$ & \\
\hline
\end{tabular}

Notes: Standard deviations are in parentheses. ${ }^{*}$ significant at $10 \%$; $* *$ significant at $5 \%$; *** significant at $1 \%$

Table VI presents these results in a regression framework. The coefficient estimates suggest that encouragement had no meaningful effect on whether or not participants submitted a project or on our combined average normalized score variable. The coefficient estimate on submission scores conditional on submitting 
(columns 5 and 6 ) are positive and quite large but as in the other columns, are statistically insignificant. Together, these findings suggest that encouragement had no effect on outcomes, the small sample size for those that submitted a project make it difficult to draw any definitive conclusions regarding that outcome.

Table VI: Effect of Encouragement Treatment

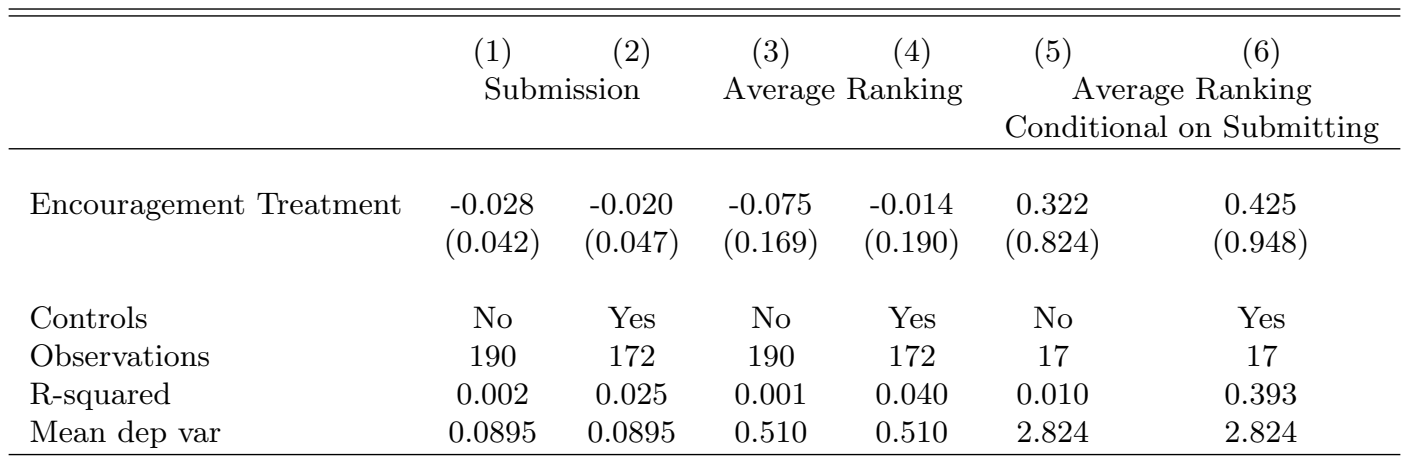

Notes: Standard errors are in parentheses. Columns 2, 4, and 6 include controls for participant gender, cgpa, year of study, whether or not they major in computer science or electrical engineering, and whether or not they have prior innovation contest experience. * significant at $10 \% ; * *$ significant at $5 \% ; * * *$ significant at $1 \%$

\subsection{Interaction Effects between Inducement and Encouragement}

We next explore whether our encouragement treatment changes the effect of inducement, for instance, by boosting the confidence of participants who do not feel as capable of innovating as innate innovators. We present the estimates from equation 1 described in section 4 in Table VII. As in Tables VI and IV, we run the analysis with and without controls for participant characteristics.

The estimates demonstrate that across all specifications, the interaction between the inducement and encouragement treatments is negative and, in some cases, quite large. However, it is important to note that we cannot rule out that the coefficients are zero or even positive. In the end, the treatment effects and interaction are explaining very little of the variation in participant performance, suggesting little role for the interaction of our two treatments on participant outcomes.

\subsection{Heterogeneous Treatment Effects}

We theorized in section 2 that the inducement treatment could vary by participant ability if inducement leads both lower ability innovators and innovators with a higher cost of innovation but similar ability as the self-selected population to participate. In particular, inducement should reduce performance among the lower ability population, but not impact it among those that simply have a higher cost of participation. 
Table VII: Joint Effect of Inducement \& Encouragement Treatment

\begin{tabular}{lcccccc}
\hline \hline & $\begin{array}{c}(1) \\
\text { Submission }\end{array}$ & $\begin{array}{c}(2) \\
\text { Average Ranking }\end{array}$ & $\begin{array}{c}(5) \\
\text { Average Ranking } \\
\text { Conditional on Submitting }\end{array}$ \\
\hline Inducement Treatment & 0.019 & 0.016 & 0.031 & -0.019 & -0.367 & -0.253 \\
& $(0.059)$ & $(0.066)$ & $(0.238)$ & $(0.267)$ & $(1.099)$ & $(1.180)$ \\
Encouragement Treatment & 0.006 & 0.018 & 0.071 & 0.151 & 0.501 & 0.683 \\
& $(0.057)$ & $(0.064)$ & $(0.230)$ & $(0.259)$ & $(1.099)$ & $(1.308)$ \\
Encouragement Treatment* & -0.073 & -0.079 & -0.318 & -0.344 & -0.902 & -0.729 \\
Inducement Treatment & $(0.084)$ & $(0.093)$ & $(0.340)$ & $(0.374)$ & $(1.823)$ & $(2.053)$ \\
& & & & & & No \\
Controls & No & Yes & No & Yes & 17 & Yes \\
Observations & 190 & 172 & 190 & 172 & 17 \\
R-squared & 0.007 & 0.030 & 0.009 & 0.051 & 0.072 & 0.424 \\
Mean dep var & 0.0895 & 0.0895 & 0.510 & 0.510 & 2.824 & 2.824 \\
\hline
\end{tabular}

Notes: Standard errors are in parentheses. Columns 2, 4, and 6 include controls for participant gender, cgpa, year of study, whether or not they major in computer science or electrical engineering, and whether or not they have prior innovation contest experience. * significant at $10 \% ; * *$ significant at $5 \% ; * * *$ significant at $1 \%$

Moreover, encouragement may differentially impact high and low ability participants if, for instance, lower ability participants are less confident than high ability participants are.

To simplify the presentation of our analysis of heterogeneous treatment effects, we present mean comparison figures and regression estimates from equation 2 below. We begin by presenting heterogeneous effects of inducement, followed by those of encouragement. ${ }^{19}$

\subsubsection{Effects of Inducement by Participant GPA}

Figure II presents the difference in mean contest performance between induced and non-induced contest participants for below and above median CGPA participants respectively. These means support our predictions that when inducement leads lower ability individuals to participate in innovation, it leads to lower innovative performance. In particular, inducement leads to a large and significant reduction in participant performance among low GPA students, but an increase in performance among high GPA students. Interestingly, the highest performers are innate low GPA students suggesting that they may have private information about their innovative capabilities that are not reflected in their academic performance.

Table VIII presents estimates of the interaction between GPA and inducement, and provides support for the mean comparisons. In particular, low GPA students suffer from inducement whereas high GPA students benefit from it. These effects seem to work both by affecting submission rates and rankings conditional on

\footnotetext{
${ }^{19}$ We did not design our study to have sufficient sample size to estimate heterogeneous effects by all four treatment groups and so we don't report these effects here. However, controlling for whether those in the inducement treatment are also in the encouragement treatment and vice versa does not change our results.
} 
Figure II: Change in Average Ranking due to Inducement by GPA

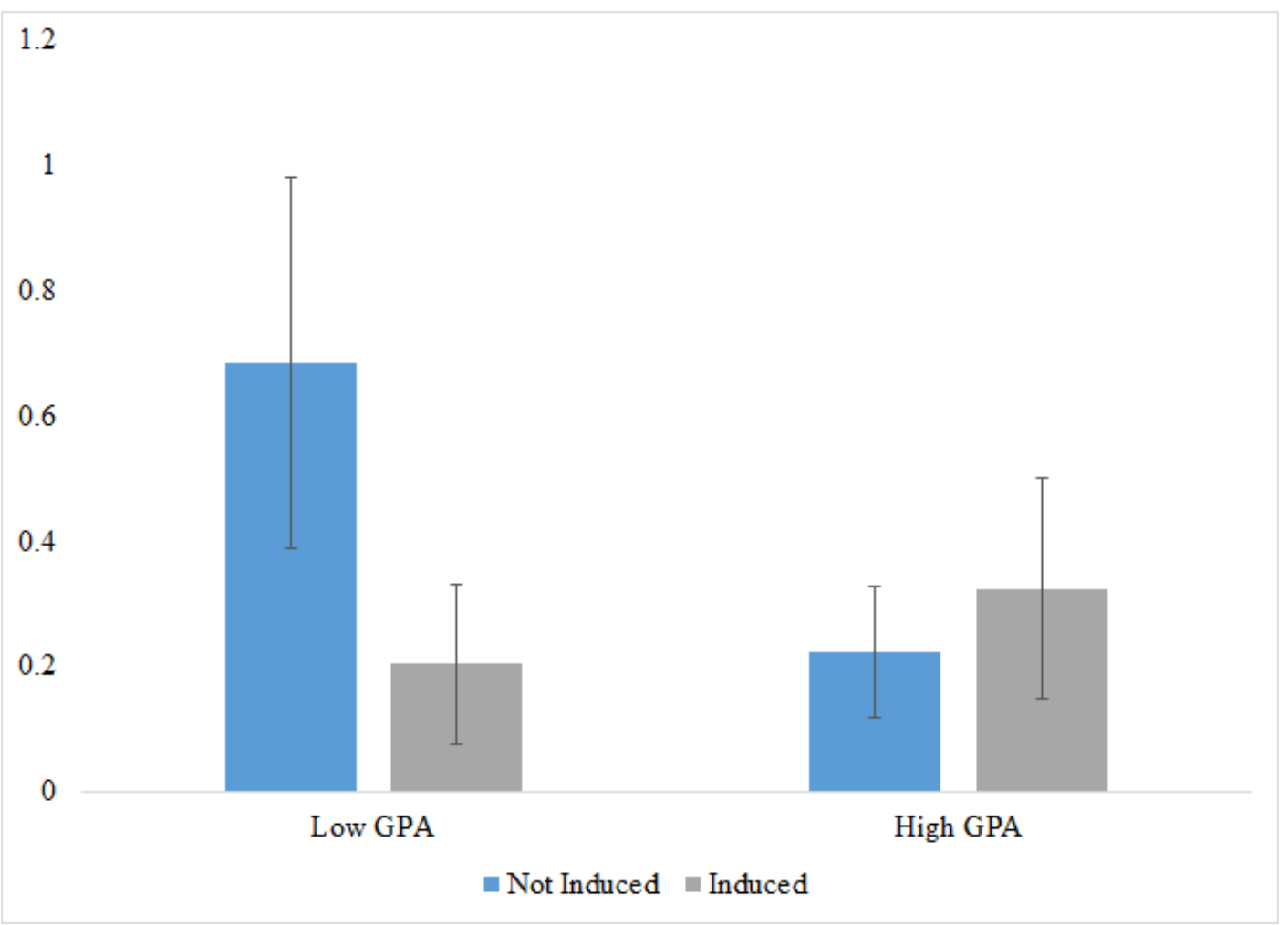


submissions. ${ }^{20}$ Appendix Table A4 demonstrates that the estimates presented in Table VIII are minimally affected by the inclusion of controls for participant characteristics, though we lose some significance.

Table VIII: Joint Effect of Inducement Treatment by GPA

\begin{tabular}{lccc}
\hline \hline & $(1)$ & $(2)$ & $(3)$ \\
& Submission & Average Ranking & $\begin{array}{c}\text { Average Ranking } \\
\text { Conditional on Submitting }\end{array}$ \\
\hline Inducement Treatment & -0.067 & $-0.480^{*}$ & $-2.068^{*}$ \\
& $(0.064)$ & $(0.259)$ & $(1.085)$ \\
Above Median CGPA & -0.059 & $-0.460^{*}$ & $-2.101^{* *}$ \\
& $(0.059)$ & $(0.238)$ & $(0.939)$ \\
Above Median CGPA* & 0.084 & $0.581^{*}$ & 2.601 \\
Inducement Treatment & $(0.085)$ & $(0.344)$ & $(1.473)$ \\
& & & 17 \\
Observations & 190 & 190 & 0.323 \\
R-squared & 0.007 & 0.024 & 3.715 \\
Mean dep var & 0.09 & 0.332 & \\
\hline
\end{tabular}

Notes: Standard errors are in parentheses. ${ }^{*}$ significant at $10 \% ; * *$ significant at $5 \% ; * *$ significant at $1 \%$

\subsubsection{Effects of Encouragement by Participant GPA}

Figure III presents the difference in mean contest performance between encouraged and not encouraged contest participants below and above median CGPA participants, respectively. As with inducement, these comparisons demonstrate that the impacts of encouragement differ by ability. Unsurprisingly, low GPA students benefit from the additional support provided by encouragement. The impacts on high GPA students are much less intuitive. Not only do they not benefit from this encouragement, but they appear to be harmed by it. ${ }^{21}$

Table IX presents the estimated impact of the interaction between participant GPA and the encouragement treatment on our three primary outcomes of interest. This Table demonstrates that encouragement negatively impacted both the likelihood of submitting a project and project quality conditional on submitting among high GPA students. The positive effect of encouragement on low GPA student performance appears to work largely by improving the quality of submitted projects. Appendix Table A5 demonstrates that the estimates presented in Table VIII are minimally affected by the inclusion of controls for participant characteristics.

\footnotetext{
${ }^{20}$ Given the relatively large standard errors on our estimates, we do not think interpreting the specific sizes of our estimates is particularly valuable, and instead focus on interpreting their signs.

${ }^{21}$ Interestingly, virtually all encouraged participants who completed the post-contest survey indicated positive experiences with the encouragement emails suggesting those who were negatively impacted by the treatment did feel as though they had been.
} 
Figure III: Change in Average Ranking due to Encouragement by GPA

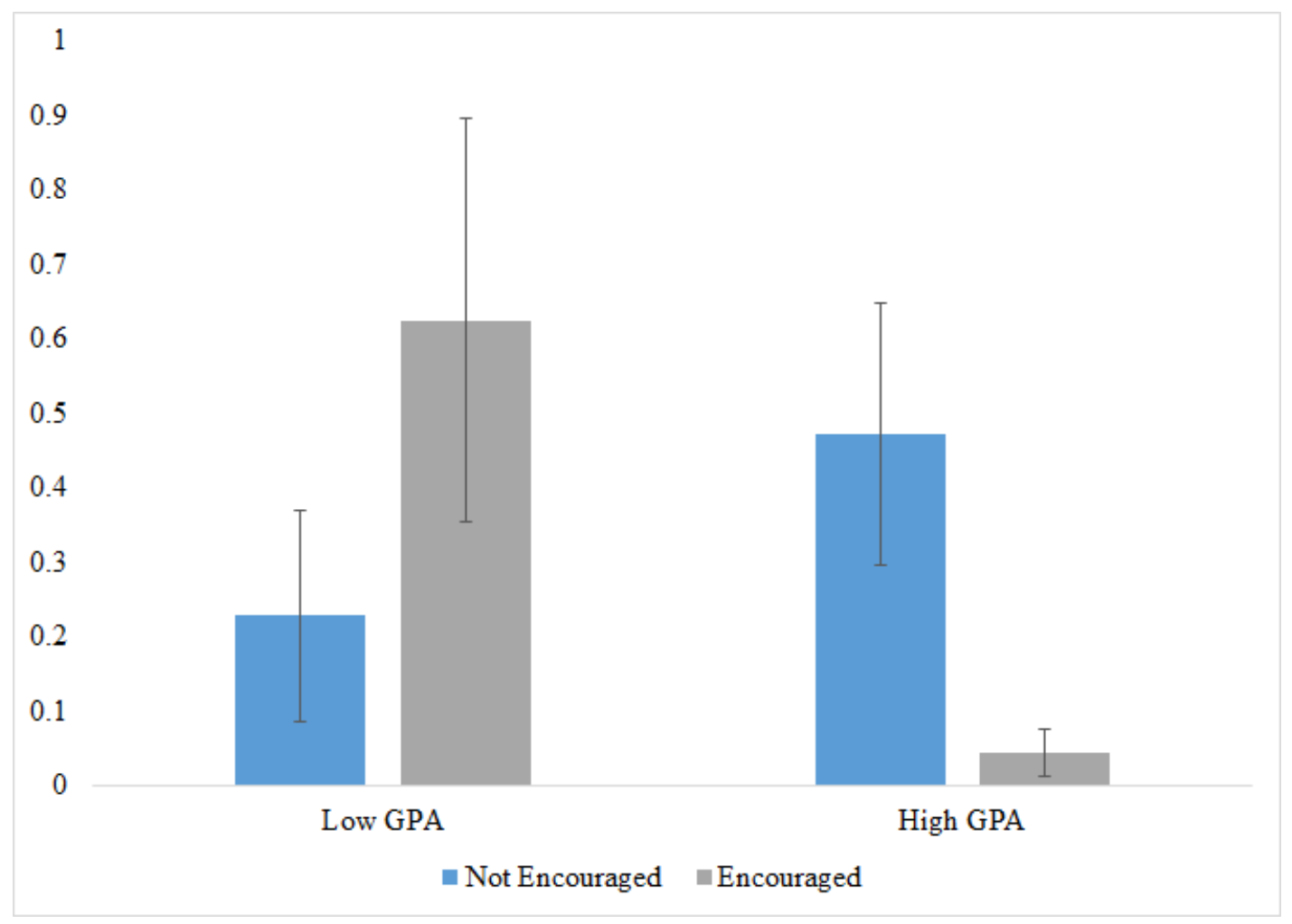

Table IX: Joint Effect of Inducement Treatment by GPA

\begin{tabular}{lccc}
\hline \hline & $\begin{array}{c}(1) \\
\text { Submission }\end{array}$ & $\begin{array}{c}(2) \\
\text { Average Ranking }\end{array}$ & $\begin{array}{c}(3) \\
\text { Average Ranking } \\
\text { Conditional on Submitting }\end{array}$ \\
\hline Encouragement Treatment & 0.052 & 0.397 & $1.890^{*}$ \\
Above Median CGPA & $(0.064)$ & $(0.256)$ & $(0.905)$ \\
& 0.052 & 0.246 & 0.675 \\
Above Median CGPA* & $(0.059)$ & $(0.237)$ & $(0.855)$ \\
Encouragement Treatment & $-0.139^{*}$ & $-0.827^{* *}$ & $-4.510^{* * *}$ \\
Constant & $(0.084)$ & $(0.338)$ & $(1.344)$ \\
& 0.073 & 0.228 & $3.110^{* * *}$ \\
Observations & $(0.045)$ & $(0.180)$ & $(0.715)$ \\
R-squared & 190 & 190 & 17 \\
Mean dep var & 0.018 & 0.037 & 0.529 \\
\hline
\end{tabular}

Notes: Standard errors are in parentheses. * significant at $10 \% ; * *$ significant at $5 \%$; *** significant at $1 \%$ 


\subsection{Exploring Mechanisms}

To better understand the mechanisms driving our estimated average effects of the encouragement and inducement treatments, we ask all participants to complete a short survey following the announcement of contest winners for the chance to win a $\$ 100$ Visa gift card. The survey questions are reported in Appendix B. Importantly, the sample of participants who completed the survey represents $41 \%$ of the total contest participant population, and, as Table $\mathrm{X}$ shows, those who completed the survey were, on average, much more likely to have submitted a project for consideration than those who did not complete it. Given this selected sample, we view this part of our analysis as suggestive rather than conclusive evidence on some of the underlying factors that may be driving our results.

Table X: Summary Statistics by Final Survey Completion

\begin{tabular}{|c|c|c|c|}
\hline & No Response & Response & p-value \\
\hline \multicolumn{4}{|l|}{ Panel A: Participant Characteristics } \\
\hline Female & $\begin{array}{c}0.313 \\
(0.043)\end{array}$ & $\begin{array}{c}0.359 \\
(0.055)\end{array}$ & 0.506 \\
\hline CS or ElecEng Major & $\begin{array}{c}0.714 \\
(0.042)\end{array}$ & $\begin{array}{c}0.692 \\
(0.053)\end{array}$ & 0.745 \\
\hline Year of Study & $\begin{array}{c}3.073 \\
(0.122)\end{array}$ & $\begin{array}{c}2.932 \\
(0.144)\end{array}$ & 0.458 \\
\hline CGPA (1-6) & $\begin{array}{c}4.417 \\
(0.083)\end{array}$ & $\begin{array}{c}4.356 \\
(0.115)\end{array}$ & 0.657 \\
\hline Prior Contest Experience & $\begin{array}{c}0.152 \\
(0.034)\end{array}$ & $\begin{array}{c}0.103 \\
(0.035)\end{array}$ & 0.326 \\
\hline Inducement Treatment & $\begin{array}{c}0.446 \\
(0.0470\end{array}$ & $\begin{array}{c}0.474 \\
(0.058)\end{array}$ & 0.706 \\
\hline Encouragement Treatment & $\begin{array}{c}0.456 \\
(0.047)\end{array}$ & $\begin{array}{c}0.538 \\
(0.058)\end{array}$ & 0.262 \\
\hline \multicolumn{4}{|l|}{ Panel B: Outcomes } \\
\hline Submission & $\begin{array}{c}0.117 \\
(0.070)\end{array}$ & $\begin{array}{c}0.639 \\
(0.173)\end{array}$ & $0.002^{* * *}$ \\
\hline Average Ranking & $\begin{array}{c}0.418 \\
(0.041)\end{array}$ & $\begin{array}{c}0.642 \\
(0.094)\end{array}$ & $0.015^{* *}$ \\
\hline Average Ranking Conditional on Submitting & $\begin{array}{c}3.249 \\
(1.236)\end{array}$ & $\begin{array}{c}3.858 \\
(0.383)\end{array}$ & 0.530 \\
\hline $\mathrm{N}$ & 114 & 76 & \\
\hline
\end{tabular}

Notes: Standard deviations are in parentheses. ${ }^{*}$ significant at $10 \%$; $* *$ significant at $5 \%$; *** significant at $1 \%$

In particular, we focus on three survey-based measures of contest engagement that we think are most relevant for understanding how our treatments affected participants' perception and experience with the contest. Specifically, we analyze whether encouragement or inducement correlates with whether or not participants spent any time on the contest problem, and if they did not submit a project for consideration, 
whether the treatments related to what prevented them from doing so. We break the latter measure of engagement into two categories that were the most frequently cited explanations for not submitting a project; not having enough time, and finding the contest problem too challenging to allow for satisfying solution strategies.

Table XI presents the results of this analysis. Consistent with the finding that neither encouragement nor inducement impacted participant outcomes on average, and with the mean comparisons presented in Tables III and V, the treatments do not appear to correlate significantly with whether or not participants invest any effort in the contest. Similarly, our treatments do not relate to the likelihood that participants failed to submit a project to the contest because they felt the problem was too challenging for them. However, as demonstrated by Column 3, we find that the encouragement treatment is associated with an approximately thirty percentage point increase in the likelihood that participants report not submitting due to time constraints. In column 4, we add controls for participant characteristics to better capture selection, at least on observables, and the estimate increases slightly. We view this finding as one consistent with the notion that the encouragement emails increased the salience of the time required for developing a solution to the contest problem and thus one that decreased submissions. ${ }^{22}$ In light of our results in Table IX, which showed that the negative effects of encouragement are concentrated on high GPA students, it seems plausible that this time salience feature from encouragement is felt most acutely by high-achieving students whose scarce time is more likely to be allocated to school work. Whether it also relates to the crowding out of intrinsic motivation remains an open question.

Table XI: Effects of Inducement and Encouragement on Survey Outcomes

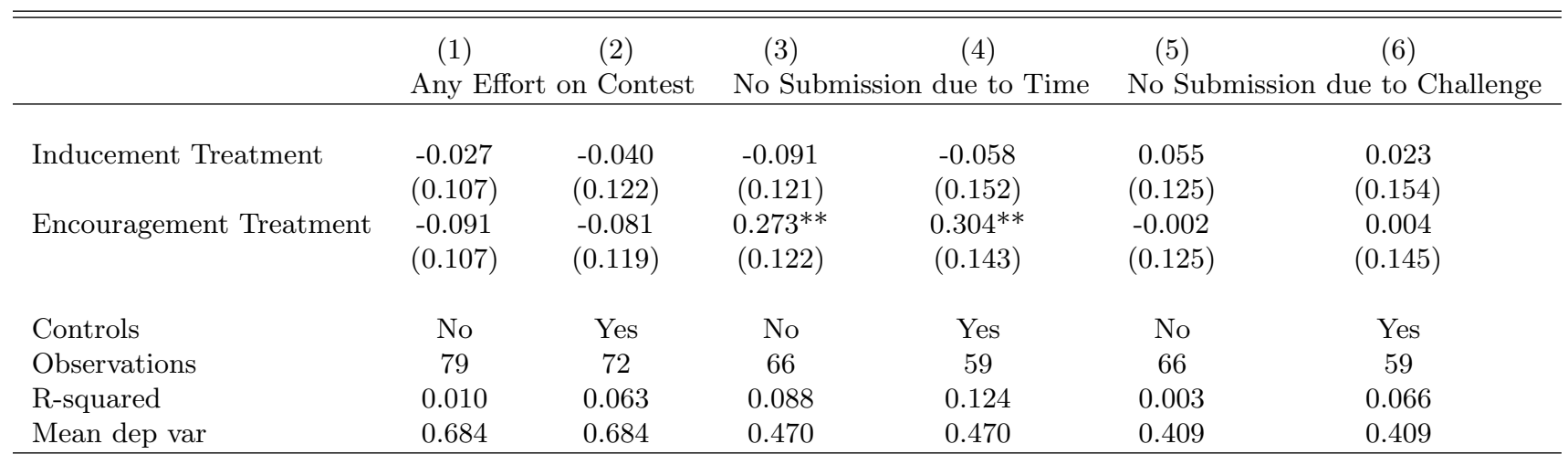

Notes: Standard errors are in parentheses. Columns 3-6 are restricted to the sample of participants who did not submit a project for consideration in the contest. Columns 2,4 , and 6 include controls for participant gender, cgpa, year of study, whether or not they major in computer science or electrical engineering, and whether or not they have prior innovation contest experience. $*$ significant at $10 \% ; * *$ significant at $5 \% ; * * *$ significant at $1 \%$

${ }^{22}$ All estimates report in Table XI are robust to using probit regressions rather than linear probability models. 


\section{Discussion}

This study provides novel and causal evidence on the scope for creating new innovators, with and without encouragement. It also sheds light on the obstacles to inducing participation and the key characteristics that distinguish those that self-identify as an innovator from those that need to be induced. Our findings demonstrate that self-selected, or innate, innovators appear to have better academic performance and are more likely to be enrolled in a major typically associated with the skills required to perform well in an app contest relative to induced innovators. Despite these quality differences, we do not observe differences in performance across the innate and induced samples, nor do we observe any effect of encouragement on participant performance. However, additional analysis of our data demonstrates that these average effects mask important heterogeneity in our sample. In fact, the impact of inducement is significantly less promising for lower ability students, as proxied by cumulative GPA, but these students are precisely the ones that benefit from the additional support provided by encouragement. The impacts on high ability students are much more surprising. Not only do they not benefit from encouragement, but they appear to be harmed by it. While our survey evidence suggests that this may due to the increased salience of the time commitment required to complete the project, it is also consistent with the idea that encouragement is crowding out intrinsic motivation in this more capable population (Benabou and Tirole, 2003).

Combined with the framework that motivated our study design, our results suggest that some people select out of innovative activities based on their expected performance, while others select out based on the costs of participating. They demonstrate that innovators can be created by subsidizing their initial entry into innovative tasks, but that targeting inducement towards those who select out due to their expected cost of participation rather than their expected performance is a more effective strategy to promote innovation. That targeted can be based on relatively easy information to obtain suggests that such a strategy may be both practical and cost effective. In particular, we find evidence that targeting can be based on information that is relatively easy to collect. In addition, we demonstrate that encouragement may also need to be targeted in order improve performance of workers who benefit from it, and importantly, to avoid harming those who do not.

Several important caveats of our study are worth highlighting. First, our study sample is comprised of undergraduate engineering students. While these students have the relevant technical capabilities to innovate and will form the backbone of the innovation economy after graduation, their relative youth may limit the generalizability of our findings to more experienced cohorts in the workplace. Second, the sample of workers who submitted a project for consideration is quite low. Although we have anecdotal evidence that a 
$10 \%$ submission rate is standard for this type of competition and, therefore, that our findings have relevant external validity, some of our null results may be in part due to lack of power. Third, while our encouragement emails were motivated by evidence on motivating employees (e.g. Amabile and Pratt, 2016), there are many ways to provide workers with encouragement aimed at enhancing performance. Therefore, while we think our finding that managerial interventions designed to encourage workers can have negative impacts on performance highlights a potentially important concern for managers of innovative firms, it remains possible that alternative interventions could avoid this shortcoming. Lastly, our measures of contest success are based on quantifiable performance metrics provided by expert evaluators. We do not have market-driven measures of innovative success, which may better reflect the ambitions of firms. How well expert evaluations of directed innovation translate into market success is an important area for future research.

\section{References}

Acemoglu, Daron, "Why do new technologies complement skills? Directed technical change and wage inequality," Quarterly Journal of economics, 1998, pp. 1055-1089.

- and Jorn-Steffen Pischke, "The structure of wages and investment in general training," Technical Report, National Bureau of Economic Research 1998.

Amabile, Teresa M and Michael G Pratt, "The dynamic componential model of creativity and innovation in organizations: Making progress, making meaning," Research in Organizational Behavior, 2016, $36,157-183$.

Azoulay, Pierre, Joshua Graff Zivin, and Gustavo Manso, "Incentives and Creativity: Evidence from the Howard Hughes Medical Investigator Program," The RAND Journal of Economics, 2011, 42, 527-554.

Barber, Brad M and Terrance Odean, "Boys will be boys: Gender, overconfidence, and common stock investment," Quarterly Journal of Economics, 2001, pp. 261-292.

Becker, Gary S, "Investment in human capital: A theoretical analysis," The Journal of Political Economy, 1962, pp. 9-49.

Beede, David N, Tiffany A Julian, David Langdon, George McKittrick, Beethika Khan, and Mark E Doms, "Women in STEM: A gender gap to innovation," Economics and Statistics Administration Issue Brief, 2011, (04-11).

Benabou, Roland and Jean Tirole, "Intrinsic and extrinsic motivation," The review of economic studies, 2003, 70 (3), 489-520.

Bureau of Labor Statistics, "Monthly Labor Review, 2013," Technical Report 2013.

Compte, Olivier and Andrew Postlewaite, "Confidence-enhanced performance," American Economic Review, 2004, 94 (5), 1536-1557.

Ederer, Florian and Gustavo Manso, "Incentives for innovation: Bankruptcy, corporate governance, and compensation systems," Handbook of Law, Innovation, and Growth, 2011, pp. 90-111. 
Elfenbein, Daniel W, Barton $\mathbf{H}$ Hamilton, and Todd $\mathbf{R}$ Zenger, "The small firm effect and the entrepreneurial spawning of scientists and engineers," Management Science, 2010, 56 (4), 659-681.

Grossman, Gene and Elhanan Helpman, "Endogenous Innovation in the Theory of Growth," Journal of Economic Perspectives, 1994, 8 (1), 23-44.

Grossman, Gene M and Elhanan Helpman, "Trade, knowledge spillovers, and growth," Technical Report, National Bureau of Economic Research 1990.

Holmstrom, Bengt, "Agency costs and innovation," Journal of Economic Behavior 83 Organization, 1989, $12(3), 305-327$.

Lyons, Elizabeth and Laurina Zhang, "Who Does (Not) Benefit from Entrepreneurship Programs?," Strategic Management Review, 2017, Forthcoming.

Nicolaou, Nicos, Scott Shane, Lynn Cherkas, Janice Hunkin, and Tim D Spector, "Is the tendency to engage in entrepreneurship genetic?," Management Science, 2008, 54 (1), 167-179.

Oettl, Alexander and Ajay Agrawal, "International labor mobility and knowledge flow externalities," Journal of International Business Studies, 2008, 39 (8), 1242-1260.

Ramirez, Octavio A, Charles B Moss, and William G Boggess, "Estimation and use of the inverse hyperbolic sine transformation to model non-normal correlated random variables," Journal of Applied Statistics, 1994, 21 (4), 289-304.

Scotchmer, Suzanne, "Standing on the shoulders of giants: cumulative research and the patent law," The Journal of Economic Perspectives, 1991, 5 (1), 29-41.

Solow, Robert M, "Technical change and the aggregate production function," The Review of Economics and Statistics, 1957, pp. 312-320.

US News \& World Report, "Best Global Universities for Computer Science," Technical Report 2016. 


\section{Appendix A Additional Tables}

Table A1: Effects of Inducement Gender

\begin{tabular}{lccc}
\hline \hline & $\begin{array}{c}(1) \\
\text { Submission }\end{array}$ & $\begin{array}{c}(2) \\
\text { Average Ranking }\end{array}$ & $\begin{array}{c}(3) \\
\text { Average Ranking } \\
\text { Conditional on Submitting }\end{array}$ \\
\hline Inducement Treatment & -0.011 & -0.087 & -0.607 \\
Female & $(0.052)$ & $(0.212)$ & $(1.002)$ \\
& 0.024 & 0.276 & 1.643 \\
Inducement Treatment* & $(0.065)$ & $(0.265)$ & $(1.103)$ \\
Female & -0.023 & -0.203 & -0.783 \\
& $(0.090)$ & $(0.366)$ & $(1.645)$ \\
Observations & & & 17 \\
R-squared & 190 & 190 & 0.216 \\
Mean dep var & 0.002 & 0.009 & 3.715 \\
\hline
\end{tabular}

Notes: Standard errors are in parentheses. ${ }^{*}$ significant at $10 \% ; * *$ significant at $5 \%$; ${ }^{* * *}$ significant at $1 \%$

Table A2: Effects of Encouragement by Gender

\begin{tabular}{lccc}
\hline \hline & $\begin{array}{c}(1) \\
\text { Submission }\end{array}$ & $\begin{array}{c}(2) \\
\text { Average Ranking }\end{array}$ & $\begin{array}{c}(3) \\
\text { Average Ranking } \\
\text { Conditional on Submitting }\end{array}$ \\
\hline Encouragement Treatment & 0.009 & 0.046 & 0.189 \\
& $(0.051)$ & $(0.207)$ & $(0.909)$ \\
Female & 0.057 & 0.289 & 0.767 \\
& $(0.060)$ & $(0.246)$ & $(0.949)$ \\
Encouragement Treatment* & -0.111 & -0.337 & $(1.845)$ \\
Female & $(0.089)$ & $(0.363)$ & 17 \\
Observations & & & 0.309 \\
R-squared & 190 & 190 & 3.715 \\
Mean dep var & 0.011 & 0.009 & \\
\hline
\end{tabular}

Notes: Standard errors are in parentheses. ${ }^{*}$ significant at $10 \% ;{ }^{* *}$ significant at $5 \% ;{ }^{* * *}$ significant at $1 \%$ 
Table A3: Effects of Encouragement \& Inducement on Alternate Measures of Performance

\begin{tabular}{lcccc}
\hline \hline & $\begin{array}{c}(1) \\
\text { Average } \\
\text { Ranking (IHS) }\end{array}$ & $\begin{array}{c}(2) \\
\text { Average } \\
\text { Normalized Score }\end{array}$ & $\begin{array}{c}(3) \\
\text { Average Normalized Score } \\
\text { Conditional on Submitting }\end{array}$ & $\begin{array}{c}\text { Average Normalized } \\
\text { Score (IHS) }\end{array}$ \\
\hline Inducement & -0.098 & -0.084 & -0.327 & -0.059 \\
Treatment & $(0.128)$ & $(0.134)$ & $(0.773)$ & $(0.091)$ \\
Encouragement & -0.028 & -0.031 & 0.473 & -0.013 \\
Treatment & $(0.128)$ & $(0.133)$ & $(0.773)$ & $(0.091)$ \\
Observations & & & & 190 \\
R-squared & 190 & 190 & 0.047 & 0.002 \\
Mean dep var & 0.003 & 0.002 & 2.824 & 0.510 \\
\hline
\end{tabular}

Notes: Standard errors are in parentheses. * significant at $10 \%$;* significant at $5 \%$; ** significant at $1 \%$

Table A4: Joint Effect of Inducement Treatment by GPA, Controls

\begin{tabular}{lccc}
\hline \hline & $\begin{array}{c}(1) \\
\text { Submission }\end{array}$ & $\begin{array}{c}(2) \\
\text { Average Ranking }\end{array}$ & $\begin{array}{c}(3) \\
\text { Average Ranking } \\
\text { Conditional on Submitting }\end{array}$ \\
\hline Inducement Treatment & -0.064 & $-0.487^{*}$ & -1.978 \\
Above Median CGPA & $(0.069)$ & $(0.277)$ & $(1.102)$ \\
Above Median CGPA & 0.081 & 0.088 & $-3.014^{*}$ \\
Inducement Treatment & $(0.094)$ & $(0.378)$ & $(1.581)$ \\
& 0.074 & 0.551 & 2.314 \\
Observations & $(0.093)$ & $(0.373)$ & $1.470)$ \\
R-squared & 172 & 172 & 17 \\
Mean dep var & 0.040 & 0.065 & 0.627 \\
\hline
\end{tabular}

Notes: Standard errors are in parentheses. All columns include controls for participant gender, cgpa, year of study, whether or not they major in computer science or electrical engineering, and whether or not they have prior innovation contest experience. * significant at $10 \% ; * *$ significant at $5 \% ; * * *$ significant at $1 \%$ 
Table A5: Joint Effect of Encouragement Treatment by GPA, Controls

\begin{tabular}{lccc}
\hline \hline & $\begin{array}{c}(1) \\
\text { Submission }\end{array}$ & $\begin{array}{c}(2) \\
\text { Average Ranking }\end{array}$ & $\begin{array}{c}(3) \\
\text { Average Ranking } \\
\text { Conditional on Submitting }\end{array}$ \\
\hline Encouragement Treatment & & & \\
Above Median CGPA & 0.067 & $0.477^{*}$ & 2.490 \\
& $(0.068)$ & $(0.273)$ & $(1.414)$ \\
Above Median CGPA*Encouragement Treatment & $-0.202^{* *}$ & $0.831^{* *}$ & $(2.619$ \\
& $(0.096)$ & $(0.387)$ & $-4.488^{* *}$ \\
Observations & $(0.092)$ & $-0.920^{* *}$ & $(1.667)$ \\
R-squared & 172 & & 17 \\
Mean dep var & 0.054 & $0.371)$ & 0.726 \\
\hline
\end{tabular}

Notes: Standard errors are in parentheses. All columns include controls for participant gender, cgpa, year of study, whether or not they major in computer science or electrical engineering, and whether or not they have prior innovation contest experience. *

significant at $10 \% ; * *$ significant at $5 \%$; *** significant at $1 \%$

\section{Appendix B Data Appendix}

\section{Inducement Treatment Emails}

The email offering a monetary incentive for contest participation sent to students in the inducement treatment is copied below.

Hello,

The 2017 UC San Diego Student Innovation Contest is offering students the opportunity to solve a real world problem and win up to $\$ 5,000$ ! Thanks to an award from the Kauffman Foundation, the contest organizers are offering a $\$ 100$ pre-paid visa card for participating in the contest. A random sample of students have been selected for this invitation-only opportunity and you are one of them.

The organizers have postponed the sign up deadline from February 1 until February 7 to allow students who receive this invitation to take advantage of this opportunity. If you would like to participate in the contest, please sign up by 6 pm on February 7 and you will automatically be awarded a $\$ 100$ visa card. For more information and to sign up for the contest, please visit: contest website.

This contest is open to all Jacobs School of Engineering undergraduate students.

Sincerely,

Contest organizer 
The email explaining the monetary incentive and sign-up deadline extension to students in the self-selected group is copied below.

Hello, Thank you for signing up to participate in the 2017 UC San Diego Student Innovation Contest. Thanks to a generous award from the Kauffman Foundation, the contest organizers are offering students a $\$ 100$ pre-paid visa card just for participating in the contest! In addition, they have invited a randomly selected set of students to sign up and also take advantage of this opportunity. To allow these students time to sign up, the organizers have postponed the start of the contest until February 8.

As a result of these changes, you will be receiving a $\$ 100$ visa card, and a description of the problem you are to solve for the contest will be announced on February 8. The organizers apologize for any inconveniences this delay may cause you. Details on how to collect your visa card will be sent to you within the next three weeks.

Sincerely,

Contest organizer 


\title{
Encouragement Treatment Emails
}

\author{
Encouragement Email \#1
}

Dear UCSD Student Innovation Contest Participant,

We hope that youre enjoying the Quarter! We wanted to reach out to tell you how happy we are that you are participating in the first ever UCSD Student Application Innovation Contest. We are confident that you will enjoy the time you spend developing your submission, and that you will gain valuable experience and knowledge through the process. By developing and refining your creativity, technical abilities, and project management skills we strongly believe that this contest will prepare you for a rewarding and innovative career. In addition, the solution you are developing for how an app can be used to help people fall asleep has the potential to have meaningful social and commercial value.

We also want to remind you that UCSD has a number of resources available for students interested in furthering their innovation capabilities, including the Institute for the Global Entrepreneur at the Jacobs School of Engineering (http://jacobsschool.ucsd.edu/globalentrepreneur/).

We look forward to seeing your innovation!

Sincerely,

Contest Organizers

Encouragement Email \#2

Dear UCSD Student Innovation Contest Participant,

You are now almost one third of the way through the first UCSD Student Innovation Contest! This also means that you still have over ten weeks to work on your submission. We hope that you have begun to make progress on your solution for helping people fall asleep faster, but if you havent had the chance to work on 
it yet, there is plenty of time remaining to develop a solution in time for the deadline.

We look forward to seeing your innovation!

Sincerely,

Contest Organizers

Encouragement Email \#3

Dear UCSD Student Innovation Contest Participant,

We hope youre enjoying Spring Break and getting some time to do things you enjoy! The contest judges and organizers are very excited about the amount of creativity, effort, and knowledge being put into finding a solution to help people fall asleep faster and are looking forward to seeing your proposals and applications. Just as a reminder, UCSD has some excellent resources for students considering careers in entrepreneurship and innovation, including the Institute for the Global Entrepreneur at the Jacobs School of Engineering (http://jacobsschool.ucsd.edu/globalentrepreneur/) and the Office of Research Affairs (http://innovation.ucsd.edu/entrepreneur/).

We look forward to seeing your innovation!

Sincerely,

Contest Organizers

Encouragement Email \#4

Dear UCSD Student Innovation Contest Participant,

We hope your Spring Quarter has gotten off to a good start! We have just over 5 weeks left until the contest deadline plenty of time for you to come up with and improve your solution to helping people 
fall asleep faster with an application. As a student in one of the 20 most innovative Computer Science and Engineering departments in the US, we are thrilled to have you working on an application that has the potential to have an impact on peoples well-being, and generate commercial success as well. In addition to the sources available to students interested in careers in innovation and entrepreneurship (http://jacobsschool.ucsd.edu/globalentrepreneur/, (http://innovation.ucsd.edu/entrepreneur/), the Kauffman Foundation, one of the contest sponsors, also has some great resources you can take advantage of (http://www.kauffman.org).

We look forward to seeing your innovation!

Sincerely,

Contest Organizers 


\section{UCSD Application Student Innovation Contest Post- Contest Participant Survey \\ * Required}

1. Why did you not sign up for the contest until you received the $\$ 100$ gift card offer to sign up?

Mark only one oval.

I was not aware of the contest until I was notified that I had been randomly selected to receive $\$ 100$ for participating

I forgot to sign up before the initial contest deadline

I did not think that I had time to participate

I did not think that I had the abilities required to participate in the innovation contest

I did not think the innovation contest was interesting or worth my time

Other:

2. Did you spend any time working on a solution for the innovation contest problem? * Mark only one oval

$\square_{\text {No }}$ Yes Skip to question 4 .

3. Why didn't you spend any time working on a solution for the innovation contest problem? Check all options that apply.

Check all that apply.

$\square$ Classes took too much of my time

$\square$ Work took too much of my time

My social life took too much of my time

$\square$ I didn't know how to begin working on the problem

$\square$ I didn't have any ideas about how to solve the problem

$\square$ I never intended to spend any time on the contest

I didn't think the contest problem was interesting enough to work on

$\square$ Other:

Skip to question 6 .

4. Did you submit a project for consideration by the contest judges? * Mark only one oval

Yes Skip to question 6 .

No 


\section{Why didn't you submit a project for consideration by the judges? Check all options that apply}

Check all that apply.

Project proved harder than I expected and I did not have enough time to finish it

$\square$ I had more school work than expected and I did not have enough time to finish my project

$\square$ I didn't think my solution was good enough to submit

$\square$ I was worried about the judges thinking poorly of my submission

$\square$ I didn't know how to submit my project

$\square$ I forgot when the deadline for submissions was

$\square$ I lost interest in the contest

$\square$ Other

6. Do you think you made the right decision by signing up to participate in the UCSD Student Innovation contest? *

Mark only one oval.

Y Yes

No

7. Did the check-in emails you received from contest organizers have any of the following impacts? Check all that apply *

Check all that apply.

They reminded me to work on the project

$\square$ They provided me with useful information on how to work on the project

$\square$ They made me feel more confident about my ability to do a good job

$\square$ They made me feel less confident about my ability to do a good job

$\square$ They annoyed me or wasted my time

$\square$ They made me feel less motivated to work on the project

$\square$ They made me feel more motivated to work on the project

$\square$ They made me feel supported by the contest organizers

$\square$ They had no impact on me

$\square$ Other:

8. How would you rate your experience with the UCSD Student Innovation contest? * Mark only one oval.

$\begin{array}{lllllll} & 1 & 2 & 3 & 4 & 5 \\ \text { Very negatively } & \bigcirc & \bigcirc & & \end{array}$


9. Will you consider participating in another innovation contest? *

Mark only one oval.

$\longrightarrow$ Yes

No

Maybe

10. How could we improve the contest going forward? *

Please provide your contact information so that you can be included in the draw to win one of $50 \$ 100$ Visa Gift Cards

11. Last Name

12. First Name

13. UCSD Email Address

Notes: Question 1 was only included in the survey given to the induced population. Question 7 was only included in the survey given to the encouraged population. 